\title{
Plataforma interactiva para la educación y el fortalecimiento de la paz: PazRed
}

\author{
Diego Tangarife ${ }^{1}$, Manuel Blanco', Esperanza M. Torres-Madroñero², y Maria C. Torres-Madronero ${ }^{{ }^{*}}$ \\ (1) Facultad de Ingenierías, Instituto Tecnológico Metropolitano, Medellín, Colombia \\ (correo-e: diegotangarife@itm.edu.co; manuelblanco@itm.edu.co; mariatorres@itm.edu.co) \\ (2) Facultad de Ciencias Sociales, Institución Universitaria Colegio Mayor de Antioquia, Medellín-Colombia \\ (correo-e: esperanza.torres@colmayor.edu.co)
}

* Autor a quien debe ser dirigida la correspondencia

Recibido Nov. 3, 2020; Aceptado Ene. 4, 2021; Versión final Feb. 10, 2021, Publicado Jun. 2021

\section{Resumen}

Este artículo analiza la interactividad como una categoría con dimensiones tecnológicas y sociales en la educación para la paz. Se presenta el diseño, desarrollo e implementación de una plataforma virtual que incorpora narrativas orales, sonoras y fotográficas de los actores en una zona de conflicto armado en Colombia. La plataforma integra componentes tecnológicos, informativos y pedagógicos a través de una cátedra virtual. La interactividad de la plataforma fue evaluada por estudiantes universitarios participantes de la cátedra virtual que dan cuenta de las potencialidades y desafíos de las tecnologías de la información (TIC) en la educación. Los resultados destacan el papel de la interactividad como componente pedagógico de plataformas virtuales, a la vez que evidencian la necesidad de mayores desarrollos en lo pedagógico e interactivo que soporten temáticas como la educación para la paz. Se concluye que la plataforma virtual propuesta (PazRed) soporta la educación para la paz en Colombia a partir de espacios interactivos digitales.

Palabras clave: interacción hombre-máquina; aprendizaje en línea; tecnologías de la información; educación para la paz

\section{Interactive platform for peace education and peace strengthening: PazRed}

\begin{abstract}
The present study examines interactivity as a category, with technological and social dimensions, for peace education. It presents the design, development, and implementation of a virtual platform that incorporates oral, sound, and photographic narratives that were gathered from an armed conflict territory in Colombia. The platform integrates technological, informational, and pedagogical components through a virtual classroom. The interactive components of the platform were evaluated by university students who participated in virtual lectures and who explained the potential and challenges of information technologies (IT) in education. The results highlighted the role of interactivity as a pedagogical component of virtual platforms. They also show the need for further development of both pedagogical and interactive tools to support and advance peace education. It is concluded that the virtual platform (PazRed) presented here can be used to support peace education in Colombia through interactive digital environments.
\end{abstract}




\section{INTRODUCCIÓN}

Una de las principales tecnologías del siglo XX es el Internet, el cual ha transformado de manera permanente las formas de acceder a la información, relacionarse con los otros y experimentar la realidad. El Internet es mucho más que tecnología, se trata de un medio de comunicación, de interacción y de organización social (Castells, 2015; Çikrıkci, 2016). Las posibilidades de interacción que oferta la actual conectividad a través de internet penetran las relaciones de poder, los procesos sociales y la noción del espacio público (Gravante y Sierra, 2018). En este sentido, preguntar por lo tecnológico invita a considerar las maneras como las personas le dan forma a su entorno social, como se articulan sus subjetividades, como interpelan sus contextos y se recrean las identidades.

La interacción hombre-computador es objeto de estudio desde diferentes áreas especialmente en lo educativo (Guney, 2019); resaltando enfoques basados en lo visual y lo auditivo. La visión es un medio de interacción, donde se encuentra la realidad mediada por computador, la realidad virtual y la realidad aumentada (Garzón y Acevedo, 2019). Por su parte, los enfoques basados en lo auditivo destacan el reconocimiento de voz y el reconocimiento del hablante, el análisis auditivo de emociones, la interacción con la música, entre otros (Bahreini et al., 2016). Adicionalmente, se destacan los sensores como medio de interacción, donde se estudia la interacción con el teclado, los sensores de movimiento, sensores de presión, entre otros (lqbal et al., 2018).

Las Tecnologías de Información y Comunicación (TIC), con su papel en la sociedad como herramientas indispensables en las actividades socioculturales actuales (Castells, 2015), dinamizan las posibilidades de interacción en el campo educativo. Las TIC materializan un tipo de sociedad donde los sujetos encuentran, en la interacción de los medios digitales, la significación, la interlocución y en muchos casos la concreción de atmósferas de participación que no son claramente identificables en el escenario abstracto de la democracia y la participación colectiva (García, 2018). De esta manera, estas tecnologías son un fenómeno social complejo que altera la intersubjetividad y la manera como las personas construyen socialmente la realidad. Las TIC son prolongaciones de nuestros sentidos, de ahí que establecen un tipo de energía personal y conciencia de nuestra experiencia con el mundo (Raja y Nagasubramani, 2018). Por ello, la relación con las TIC involucra nuevas preguntas a la manera como los sujetos aprehenden y comprenden su contexto y como le dan forma a su propia subjetividad. Las TIC da lugar a otras maneras de conocer (Raja y Nagasubramani, 2018) y tienen un lugar central en procesos de diseño y experimentación.

La interactividad tiene una dimensión perceptiva-emocional que involucra la experiencia sensorial, cognoscitiva y emocional. Esta dimensión se evidencia en escenarios donde las TIC median procesos de formación virtual con temas de alta sensibilidad como son los conflictos armados o la paz. Ejemplo de estos escenarios digitales son los portales de Internet para la documentación, exhibición y sensibilización de eventos históricos, donde las personas pueden interactuar, consultar y aprender de su historia de forma didáctica (Marschall, 2013). Entre estas plataformas se encuentran: Europeana, la cual permite navegar contenido digital relacionado con historia y patrimonio cultural de Europa (Petras et al., 2017), el Museu Da Pessoa en Brasil, que ensambla una colección de historias de vida en formato de audio y video (Vicentini y Kahn, 2019), y la plataforma History Matters que permite navegar por contenidos pedagógico digitales relacionados con la historia de EE.UU (Okolo et al., 2007). Se evidencia que las TIC emergen como el medio de conservación tanto de la memoria histórica como la memoria colectiva, no solo como repositorios de información, sino como escenarios de interlocución, reinterpretación y experimentación de la realidad (Scolari, 2015).

Por su parte, la enseñanza a través de las TIC implica considerar aspectos complejos de tipo histórico, político, cultural y tecnológico, que articulan una nueva experiencia. En este sentido, abordar la interactividad evidencia la relación de la tecnología con la educación. En temas de alta complejidad social como la educación para la paz, las TIC abren un abanico de posibilidades. La educación para la paz se instala en el mundo como una necesidad global a partir de las grandes guerras mundiales (Gómez, 2015). Con el movimiento de la Escuela Nueva y con el apoyo institucional de la UNESCO, la educación para la paz se enriquece con los ideales de no violencia, la investigación por la paz y el desarrollo (McEwan y Benveniste, 2001; Le, 2018). La interactividad en los procesos de educación de paz demanda comprensiones complejas del sujeto con lo tecnológico, con el conocimiento y con las sensibilidades que se requieren en el abordaje de la construcción de paz en contextos con conflictividades persistentes en el tiempo (Gil, 2006).

Este artículo presenta el diseño, implementación y evaluación de una plataforma virtual desarrollada a partir de la reconstrucción de la memoria histórica del conflicto armado colombiano en la región del occidente de Antioquia. La plataforma se proyecta como una herramienta pedagógica que soporte procesos de educación para la paz en niveles universitarios. Los contenidos digitales incluidos en la plataforma permiten la interactividad de los sujetos con componentes de reconstrucción de la memoria, por tanto, la evaluación del sistema se realiza en términos de su usabilidad. El articulo presenta inicialmente los referentes teóricos relacionados con interactividad, educación virtual y educación para la paz, que sirvieron de base para el diseño de la plataforma. Entonces, se presenta el diseño e implementación de la plataforma y la cátedra 
virtual. Finalmente, se realiza su evaluación de la usabilidad de la plataforma a partir de la percepción de más de 100 estudiantes que cursaron la cátedra virtual de paz.

\section{OTROS ANTECEDENTES}

En esta sección se revisan los referentes teóricos que fundamentaron el diseño y desarrollo de la plataforma PazRed. Primero, se revisa la conceptualización de interactividad y su relación con los procesos educativos. Posteriormente, se presenta una breve revisión de la educación virtual y la última sección se centra en el marco de referencia de educación para la paz. La plataforma interactiva descrita en este articulo incorpora los conceptos de interactividad, educación virtual y educación para la paz.

\section{La interactividad}

La interactividad a través de las TIC es un elemento central para abordar la relación con los medios digitales y por lo tanto una categoría central de las actuales teorías de la comunicación (Scolari, 2015). La interactividad hace referencia a la interrelación, interlocución, acoplamiento, diálogo e intercambio entre las personas y las tecnologías. Esta interactividad tiene dimensiones técnicas que vinculan la capacidad y velocidad de respuesta, la facilidad de acceso, entre otras, pero que además incluye la relación transformativa entre el usuario y el medio (Scolari, 2015). En este sentido, la interactividad incorpora: una dimensión funcional por la utilidad y características de intercambio que contiene; una dimensión de producción y consumo simbólico, al tener lugar en un escenario de interlocución y encuentro con otros sujetos interconectados de manera reticular a través de la tecnología entre sí (Scolari, 2015). El concepto de interactividad es abordado por la comunicología y las ciencias informáticas como una categoría que adquiere interés desde el desarrollo de la comunicación en masas en el siglo XIX. Este concepto apela a la interacción entre el emisor y el receptor, así como, al diálogo que resulta de la retroalimentación. Esta capacitad de interactuar se amplía de manera exponencial con los avances tecnológicos (Lorenzo y Martínez, 2010).

Para Lorenzo y Martínez (2010), el concepto de interactividad está relacionado con la entropía, o la medida de incertidumbre que existe ante un conjunto de mensajes. La interactividad reduce la entropía permitiendo la ubicación de contenidos y personas, fomentando un dinamismo vital en el proceso de comunicación social (Lorenzo y Martínez, 2010). Por otra parte, Scolari (2015) propone este término para aludir a la capacidad de conversación con las máquinas. Scolari (2015) retoma postulados de Ted Nelson con la noción del "hiperepisodio", en el cual un tele-usuario toma decisiones ante los contenidos, crea recorridos alternativos, de igual manera, puede sumar contenidos, generar otros finales o procesos a medida que recorre la trama (Scolari, 2015). Para otros, la interactividad representa una parte de la Web 2.0, como una de las grandes dimensiones que se entrecruzan y que demanda nuevas alfabetizaciones ante los cambios culturales, que se denominan líquidos (Area y Pessoa, 2012).

Autores como Fainholc (1999) comprenden la interactividad como parte de los recursos y materiales didácticos dentro de procesos educativos. El diálogo y la interactividad se corporizan en mediaciones donde el estudiante asume un rol protagónico. Estos espacios pasan a cumplir funciones en los procesos de aprendizaje, al establecerse como medios de diálogo y de acceso a la información (Fainholc, 1999). Otros autores, ubican la interactividad como parte de un modelo complejo que propone nuevos campos para comprender lo educativo y lo investigativo en un contexto físico-virtual (Cenacchi, 2015). En este articulo asumimos la interactividad como la relación de los sujetos con las tecnologías, específicamente las TIC y su aplicación en los procesos educativos. La comunicación entre los medios, los mensajes y los sujetos a través de las TIC demanda nuevas lecturas, en la medida que la rapidez, la interconectividad y la posibilidad de incorporar lenguajes diversos, se amplía con el ecosistema comunicativo (Gómez y Hernán, 2016).

\section{La educación virtual o educación en línea}

La educación virtual o educación en línea es el proceso de formación que se lleva a cabo a través de dispositivos interconectados, a partir de la conexión y el uso de las TIC. Este tipo de educación redefine las relaciones tradicionales entre docentes, estudiantes y los escenarios de interacción cara a cara, vinculan otros modos de conectividad donde ni la presencialidad, ni la sincronía son indispensables. Las TIC en lo educativo entablan un nuevo paradigma educativo, donde se establecen nuevas connotaciones del tiempo y el espacio, así como otras posibilidades de relación entre los actores educativos y de estos con el saber (Cabero y Llorente, 2007). La incorporación de las TIC en la educación ha promovido nuevos espacios de enseñanza, a la vez que impulsa la generación de nuevo conocimiento y de difusión, principalmente en la educación superior (De-la-Hoz-Franco y Martínez-Palmera, 2019).

Debido al auge de la educación virtual en nuestra época, se ha generado una serie de reflexiones académicas que la sitúan más allá de la incorporación de instrumentos. La educación virtual es parte de un tipo de imaginación e inteligencia colectiva que más allá de lo puramente cognitivo, implica el trabajo conjunto, un punto de intersección de ideas y personas (Lévy, 1997). Dicha inteligencia, como lo expone Lévy (1997) está repartida. Se trata de un conocimiento que ya no se encuentra concentrado debido a los usos tecnológicos. 
En este sentido, la educación virtual es un espacio de encuentro con un tipo de conocimiento fragmentado, en flujo permanente, donde se diluye la certeza. En estos términos, constituir el espacio del conocimiento involucra instrumentos institucionales, técnicos, conceptuales para navegar la información (Lévy, 1997). Esta comprensión propuesta por el autor desborda entender la inteligencia como algo meramente cognitivo, se trata de abogar por el trabajo conjunto, que vincula ideas y personas.

\section{Educación para la paz}

La educación para la paz se establece como una necesidad de la humanidad después de la segunda guerra mundial (Gómez, 2015), impulsada desde organización como la UNESCO. A pesar de sus inicios a mediados del siglo XX, no se ha logrado el desarrollo de las competencias ciudadanas que conlleven a sociedades más pacíficas. Por ello, en el año 2015, la Organización de las Naciones Unidas (ONU), en la apuesta por establecer objetivos de desarrollo sostenible, definió el objetivo 16: paz, justicia e instituciones fuertes, el cual busca comprometer a los países miembro a incrementar sus esfuerzos por construir sociedades en paz y prosperas (Fernández-Rodriguez,2018).

La educación para la paz invita a considerar la complejidad de los relatos que incorporan las ciencias sociales, pero además el alcance político y ético que demanda la formación ciudadana. En este sentido, en los últimos años se presentan avances en cuanto a la formación en estas áreas, que incorporan estrategias que impacten de forma significativa y práctica la vida cotidiana, el manejo de conflictos, el respeto por las diferencias y el manejo emocional de situaciones (Hymel y Darwich, 2018). Lo anterior, pone como reto al sistema educativo y a los profesores la incorporación de la creatividad en la pedagogía para movilizar en los estudiantes relaciones más humanas con el contexto, la familia y la problemática social. Así como la posibilidad de comprender temas complejos que involucren lo humano, más que lo informativo.

La educación para la paz en los niveles escolares usualmente se integra con la clase de lenguaje para desarrollar la competencia de la asignatura con algunos de los ejes temáticos de la cátedra, como competencias ciudadanas y manejo de conflictos en su mismo contexto (Paredes et al., 2018). Sin embargo, continúa siendo un desafío abordar temas que reclaman un tipo de formato sensible, como son las narrativas de actores que ha estado inmersos en el conflicto armado. La educación para la paz, que incorpora la memoria colectiva, y esta a su vez como un terreno en disputa (Barash, 2016), desborda los modelos educativos bancarios (Freire, 2014), demanda otro tipo de relación con el conocimiento y con la tecnología que incorpore la sensorialidad, la emocionalidad y lo cognitivo, en un mismo nivel de importancia. Con la globalización, los temas de educación para la paz se diversifican, en la medida que el acceso tecnológico posibilita nuevos escenarios para el conocimiento, lo que amplía las metodologías, los modelos y modalidades de formación que no se restringe a la formación en las tecnologías, la ingeniería y las matemáticas, sino que abarca temas de complejidad social en el marco de las ciencias sociales y los estudios de paz (Torres-Madroñero y TorresMadroñero, 2020).

\section{METODOLOGÍA}

Esta investigación consistió en el desarrollo, aplicación y validación de una plataforma virtual enfocada en la educación para la paz dirigida a estudiantes de educación superior. La cátedra virtual de paz PazRed se construyó a partir de las narrativas de habitantes de la zona del occidente de Antioquia, quienes han vivenciado diferentes sucesos del conflicto armado en el país. El trabajo de campo a partir de herramientas participativas (Mannay, 2017) para elaborar narrativas de memoria del conflicto armado en las zonas de Dabeiba y Frontino se describe en (Torres-Madroñero y Torres-Madroñero, 2020). Estas narrativas fueron el insumo para el diseño del curso y de la plataforma virtual. Se diseñó una plataforma virtual compuesta por una cátedra de paz virtual, material pedagógico abierto y un repositorio con la información digitalizada del proceso de investigación. La validación del componente educativo se realizó con estudiantes matriculados en la cátedra virtual PazRed, analizando diferentes dimensiones de la interactividad que posibilitó la plataforma. Las siguientes secciones describen en detalle las etapas de diseño de la plataforma virtual PazRed, su implementación, y la evaluación del componente educativo.

\section{Diseño plataforma virtual PazRed}

La plataforma virtual PazRed se proyectó como un escenario virtual didáctico que incorpore material narrativo de diferentes tipos, esto es, donde tengan lugar todas las producciones participativas diseñadas con los actores en los territorios (Mannay, 2017): textos escritos, fotográficos, audios y gráficos. El carácter cualitativo de la información, así como la complejidad narrativa de este tipo de registro, requirió el diseño de una plataforma que no se limite al almacenamiento y presentación de la información, sino que posibilite un tipo de interacción sensible y emocional con los usuarios. Ello significa, que las relaciones con los datos en la plataforma posibilitan un proceso interpretativo, que más allá del ejercicio de conocer, permita comprender de verdad lo acontecido con el conflicto armado y la construcción de paz. 
El diseño de la plataforma se construyó a través de un proceso colaborativo, identificando los requisitos funcionales y no funcionales. Partiendo de la idea de incluir tres componentes en la plataforma, denominados investigativo, informativo y educativo. El componente investigativo buscó administrar los datos cualitativos recolectados en el trabajo de campo. El usuario central de este componente es el grupo de investigación que, a partir de un proceso de aplicación de metodologías participativas, reúne información y almacena en un repositorio datos etiquetados y categorizados. Se trata de una sección donde se hace evidente un primer nivel de interpretación, consistente en la asignación de categorías a la información. El componente informativo corresponde a la sección de acceso abierto. A partir de los datos recolectados en campo, se buscó la construcción de materiales digitales a partir de un ejercicio de interpretación. Este componente se fundamenta en el trabajo investigativo, pero cumple una función comunicativa e informativa en la plataforma. Por último, el componente educativo integra los módulos MOOC de la cátedra virtual de PazRed. Este componente está enfocado a administrar tanto los contenidos de los cursos, como dar acceso a los estudiantes matriculados al proceso formativo. Para dar respuesta a los requisitos del sistema, se utilizó un patrón de software MVC (Modelo Vista Controlador) (Thakur y Pandey, 2019), empleando un enfoque orientado a objeto combinado con la programación funcional. La plataforma tecnológica consta de tres capas: un módulo de seguridad, un módulo de aplicación y un módulo base de datos. La Figura 1 presenta el diagrama de las tres capas del patrón MVC para la plataforma PazRed.
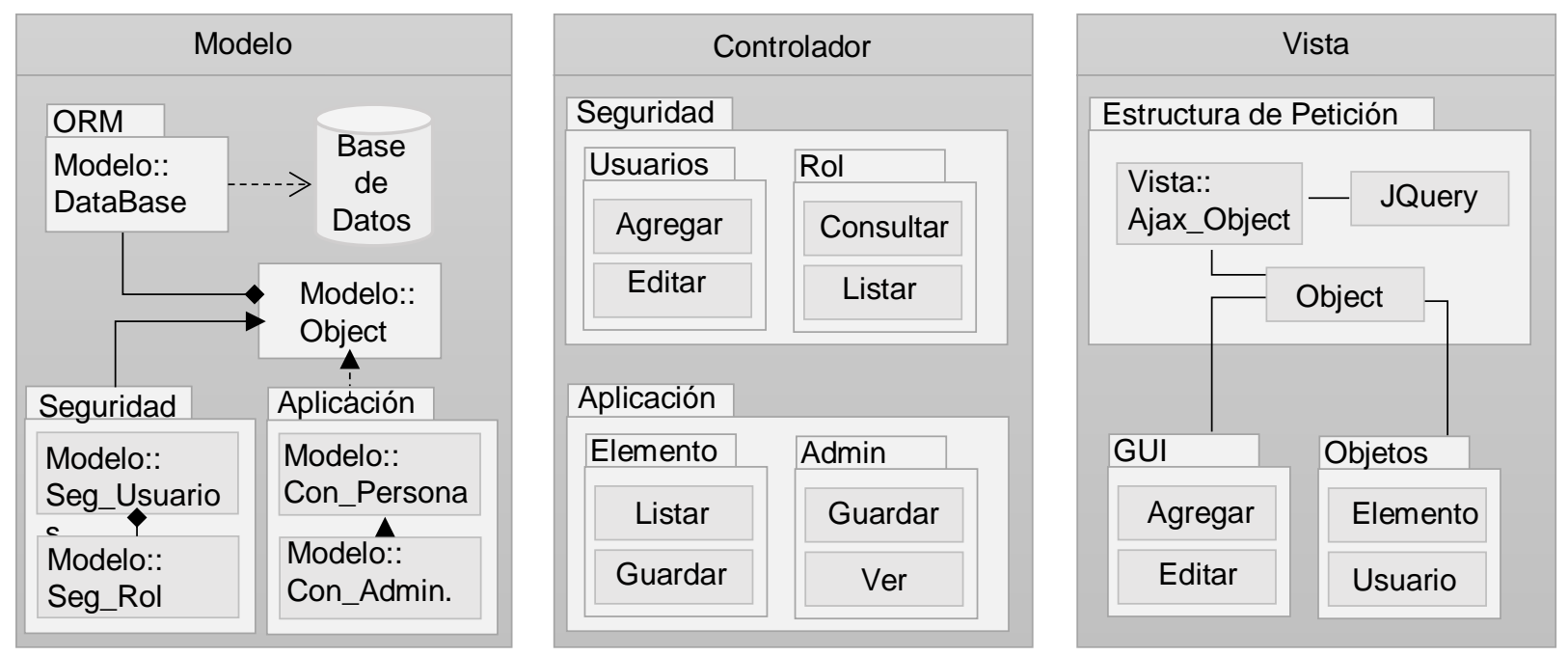

Fig. 1. Patrón de diseño de la aplicación PazRed

\section{Modelo de datos}

Debido a los propósitos diferenciables que buscan los tres componentes de PazRed, se definieron tres bases de datos independientes que permiten almacenar y acceder a la información de acuerdo con cada uno de los componentes. La base de datos del componente investigativo administra los datos de campo: fotografías, audios de entrevistas, documentos, recorridos guiados y archivos generados de talleres. Estos datos se consideran reservados, dado que incluyen material sensible, como los datos personales de los entrevistados, las entrevistas completas, fotografías y audios sin editar. Entre los datos almacenados en esta sección se incluyen los consentimientos informados de cada participante de la investigación de campo. Por su parte, la base de datos del componente informativo administra los datos procesados (es decir, fotografías editadas, Podcast, etc.) que se encuentran disponibles a través de la página web pública. Finalmente, la base de datos del componente educativo administra la información requerida para los módulos de la cátedra virtual. Se utiliza un sistema gestor de base de datos que permite organizar la información de acuerdo con los requerimientos de PazRed.

\section{Implementación}

La plataforma tecnológica hace uso de la arquitectura cliente/servidor bajo el protocolo HTTP (Protocolo de comunicación de Internet) tanto para las peticiones como para las respuestas. Debido a las características funcionales del proyecto, se usa el CMS Wordpress para la integración de la plataforma. CMS Wordpress facilita la administración del contenido y la integración de plugins que puedan cubrir los requerimientos visuales y de presentación de la información. Para el componente investigativo, se plantea el uso de un sistema paralelo que realice la administración de la data almacenada en la base de datos empleando el framework Yii2 por su practicidad en el despliegue y administración, además de proveer un entorno funcional eficiente y seguro. Además, se el LMS Moodle para la administración del contenido de la cátedra virtual, 
considerando que también facilita la administración de roles de usuario que se acoplan correctamente con las directrices del proyecto.

\section{Interfaz Gráfica de Usuario}

La vista está diseñada para ser dinámica y eficiente, para lograrlo hace uso de una arquitectura objetual, en la cual los métodos y los objetos son importados a medida que se van solicitando. Por ejemplo, cuando se accede al componente pedagógico o aula virtual en el sitio web, una clase GUI (Interfaz Gráfica de Usuario) solo muestra en pantalla el formulario de registro para nuevo usuario; cuando se accede con un nombre de usuario y una contraseña previamente registrados, la clase GUI importa y agrega nuevas vistas en la pantalla. Esto permite una navegación rápida y fluida de los diferentes componentes de la plataforma. Para el diseño gráfico de la plataforma se tiene en cuenta los elementos de la naturaleza fuego, aire, tierra y agua. Cada elemento se asocia a un significado en el proceso de reconstrucción de memoria colectiva. La representación de los elementos se mantiene en los tres componentes de la plataforma, brindando un contexto y homogeneidad a la aplicación.

\section{Evaluación de la plataforma}

La plataforma interactiva de la cátedra de paz PazRed tiene como dominio http://www.pazred.com.co/. En este sitio se encuentran los tres componentes de la plataforma. Los contenidos digitales tanto en la sección informativa como en la cátedra virtual incluyen: imágenes, documentos, videos, y objetos virtuales de aprendizaje (OVA). Para evaluar el componente educativo y la plataforma, se realizó una encuesta a los estudiantes matriculados en la cátedra virtual durante el periodo 2020-1. Los estudiantes pertenecen, en su mayoría, a instituciones de educación superior de Antioquia (Colombia). La cátedra virtual de paz se desarrolló en un periodo de 4 meses donde el estudiante podía desarrollar cada uno de los módulos de acuerdo con su ritmo de aprendizaje.

Para evaluar la plataforma se aplicaron dos encuestas: la primera se realizó una vez finalizado el primer módulo de la cátedra, garantizando que los estudiantes hayan explorado la plataforma. La segunda encuesta se realizó al cierre del curso virtual. En ambas encuestas se evaluó la percepción de los estudiantes sobre la usabilidad de la plataforma (ver Tabla 1). Para la segunda encuesta, se agregaron las preguntas presentadas en la Tabla 2 con el propósito de evaluar la percepción final de los estudiantes. Para las preguntas 1 a 12 se solicitó a los estudiantes asignar una valoración en la escala de uno a cinco, siendo uno la puntuación mínima (muy mal - muy insatisfecho) y cinco la puntuación máxima (muy bien - muy adecuado). La pregunta 13 se diseñó como una pregunta de selección para determinar cuál de los tipos de contenidos digitales fue de mayor acogida para los estudiantes.

Tabla 1. Preguntas para evaluar la percepción de los estudiantes respecto a la usabilidad de la plataforma PazRed

\begin{tabular}{|l|l|}
\hline No. & Pregunta \\
\hline 1 & ¿Le parece adecuada la presentación y estructura del sitio? \\
\hline 2 & ¿Los colores de los textos en los menús son legibles y se identifican claramente? \\
\hline 3 & ¿Las imágenes que se presentan son adecuadas al mensaje que se desea transmitir? \\
\hline 4 & ¿Al hacer clic en algún contenido o enlace halló la información que esperaba encontrar? \\
\hline 5 & $\begin{array}{l}\text { ¿Los nombres de los enlaces son suficientemente descriptivos y coherentes con el contenido en las páginas } \\
\text { hacia las cuales llevan? }\end{array}$ \\
\hline 6 & ¿Pudo encontrar la manera de volver atrás y avanzar sin usar los botones del navegador? \\
\hline 7 & ¿Los íconos presentes en el sitio, le parecen lo suficientemente legibles, reconocibles, y explicativos? \\
\hline 8 & ¿La opción de buscar le permitió encontrar la información que quería encontrar? \\
\hline 9 & ¿Los contenidos que se desarrollan en la plataforma generan reflexividad y conocimiento del tema central? \\
\hline
\end{tabular}

Tabla 2. Preguntas para evaluar la percepción final de los estudiantes sobre su experiencia en PazRed

\begin{tabular}{|l|l|}
\hline No. & Pregunta \\
\hline 10 & ¿Cómo califica su experiencia en la cátedra virtual PazRed? \\
\hline 11 & ¿Cómo califica la pertinencia de las temáticas abordadas respecto a la educación para la paz? \\
\hline 12 & ¿Cómo califica los contenidos digitales de la cátedra virtual de paz? \\
\hline 13 & ¿Cómo califica la plataforma pazred.com.co? \\
\hline 14 & $\begin{array}{l}\text { ¿Cuál fue el material que más disfruto durante su acercamiento a la plataforma? (lecturas, videos, historias de } \\
\text { vida, microrrelatos, juegos dinámicos, podcast) }\end{array}$ \\
\hline
\end{tabular}

\section{RESULTADOS}

A continuación de describen los resultados obtenidos en cada etapa del diseño de la plataforma PazRed. Primero se presentan los requisitos funcionales y no funcionales construidos a partir del trabajo colaborativo, luego se describe la implementación de la plataforma y la interfaz gráficas. Finalmente, se presentan los resultados de percepción de los estudiantes que participaron de la cátedra virtual durante 2020-I. 


\section{Requisitos funcionales y no funcionales}

A partir de talleres y conversatorios realizados con un equipo interdisciplinar, se definieron los requisitos funcionales y no funcionales de la plataforma PazRed. La Tabla 3 presenta los requisitos funcionales para cada componente de la aplicación.

Tabla 3. Requisitos funcionales plataforma virtual PazRed

\begin{tabular}{|c|c|}
\hline Requisito & Descripción \\
\hline $\begin{array}{l}\text { Repositorio de } \\
\text { datos }\end{array}$ & $\begin{array}{l}\text { Propósito: Sección de la plataforma donde se almacena y categoriza la información recolectada } \\
\text { en campo. El material incluye entrevistas semiestructuradas, fotografías y talleres. } \\
\text { Usuarios: Esta sección es para uso limitado al grupo de investigación. } \\
\text { Características: } \\
\text { Permite almacenar audios, textos, fotografías, y recorridos guiados } \\
\text { Cada material es categorizado y etiquetado con una de las zonas de estudio } \\
\text { Se almacena el nombre de la persona a cargo del levantamiento de los datos } \\
\text { Se almacena el consentimiento informado en el caso de entrevistas }\end{array}$ \\
\hline $\begin{array}{l}\text { Sección de } \\
\text { acceso abierto }\end{array}$ & $\begin{array}{l}\text { Propósito: Sección de la plataforma de acceso público. Aquí se encuentran materiales que ya han } \\
\text { sido organizados, interpretados y transformados en relatos digitales. } \\
\text { Usuarios: abierta al publico } \\
\text { Características: } \\
\text { "Acerca de nosotros": presenta las generalidades del proyecto PazRed } \\
\text { "Explorar": permite navegar a través de un mapa interactivo fotografías, audios y documentos de } \\
\text { sucesos representativos de las zonas estudio. } \\
\text { "Cátedra de paz": incluye la descripción del curso virtual, las unidades temáticas y los objetivos } \\
\text { de formación. } \\
\text { "Contáctenos": despliega un formulario para tramitar preguntas, dudas y otros intereses alrededor } \\
\text { del proyecto. } \\
\text { "Actores aliados": presenta las alianzas y actores institucionales que se suman a PazRed, tanto } \\
\text { en lo internacional, nacional y local. } \\
\text { "Nuestro equipo": describe los perfiles de los investigadores que fueron parte de las diferentes } \\
\text { etapas del proyecto. }\end{array}$ \\
\hline Cátedra virtual & $\begin{array}{l}\text { Propósito: Sección de la plataforma con el componente educativo. Incluye los cursos MOOC de } \\
\text { la cátedra. } \\
\text { Usuarios: Sección de uso limitado a estudiantes y profesores de la cátedra, así como al } \\
\text { administrador del curso } \\
\text { Características: } \\
\text { Los estudiantes tienen acceso a los módulos virtuales de la cátedra de paz. El desarrollo de los } \\
\text { módulos no es línea, cada estudiante tiene la libertad de navegar y desarrollar el curso de acuerdo } \\
\text { con su interés. } \\
\text { Los módulos incluyen lecturas, videos, podcast, juegos interactivos, infografías y microrrelatos } \\
\text { digitales. } \\
\text { Se incluye un foro para la resolución de dudas del proceso formativo } \\
\text { Los docentes realizan a través de la plataforma la evaluación y seguimiento de los estudiantes. } \\
\text { El administrador del curso se encarga de crear nuevos grupos, realizar el registro y matricula de } \\
\text { estudiantes, asignar docentes, y organizar el material de los módulos }\end{array}$ \\
\hline
\end{tabular}

En el componente investigativo se definió la construcción de un repositorio de datos para el almacenamiento de los datos recolectado en campo (entrevistas, documentos, fotografías); dado que en el proceso de salidas de campo participaron personas víctimas de conflicto armado, la información sin editar es altamente sensible, por lo cual se determinó que a esta información solo podría acceder los investigadores del proyecto. En el componente informativo se encuentra el sitio web que aloja toda la plataforma y donde se muestra la información referente al proyecto, es un sitio abierto con información editada a la que todas las personas pueden acceder. Finalmente, en el componente pedagógico se tienen tres tipos de usuarios: el profesor, encargado de administrar el material de la cátedra, los estudiantes que cursan la cátedra, y el administrador encargado del manejar todos los contenidos y registro de usuarios. La Tabla 3 presenta en detalle los propósitos, usuarios y características definidas para cada componente.

Por otra parte, de la construcción colaborativa se definieron los requisitos no funcionales, los cuales permiten garantizar aspectos de calidad del software, tales como rendimiento, fiabilidad, exactitud, seguridad y usabilidad. Entre los requisitos no funcionales incluidos en la plataforma PazRed se destacan los mensajes para advertir errores en el registro de datos (ejemplo: datos incompletos, usuarios no registrados, errores en contraseñas). Adicionalmente, se buscó que la plataforma sea escalable y actualizable permitiendo futuras mejoras. Finalmente, y buscando una mejor interactividad como la plataforma, se definió que tanto el 
componente informativo como pedagógico incluyera animaciones, juegos, y despliegue de imágenes y fotografías, brindando contexto al propósito de la aplicación como herramienta educativa para la reconstrucción de la memoria histórica desde narrativas del conflicto.

\section{Plataforma PazRed}

La plataforma final PazRed se encuentra ubicada en un servidor propio, al cual se puede acceder a través del dominio www.pazred.com.co. La Figura 2 muestra la integración de los tres componentes y las herramientas empleadas para el desarrollo de PazRed.

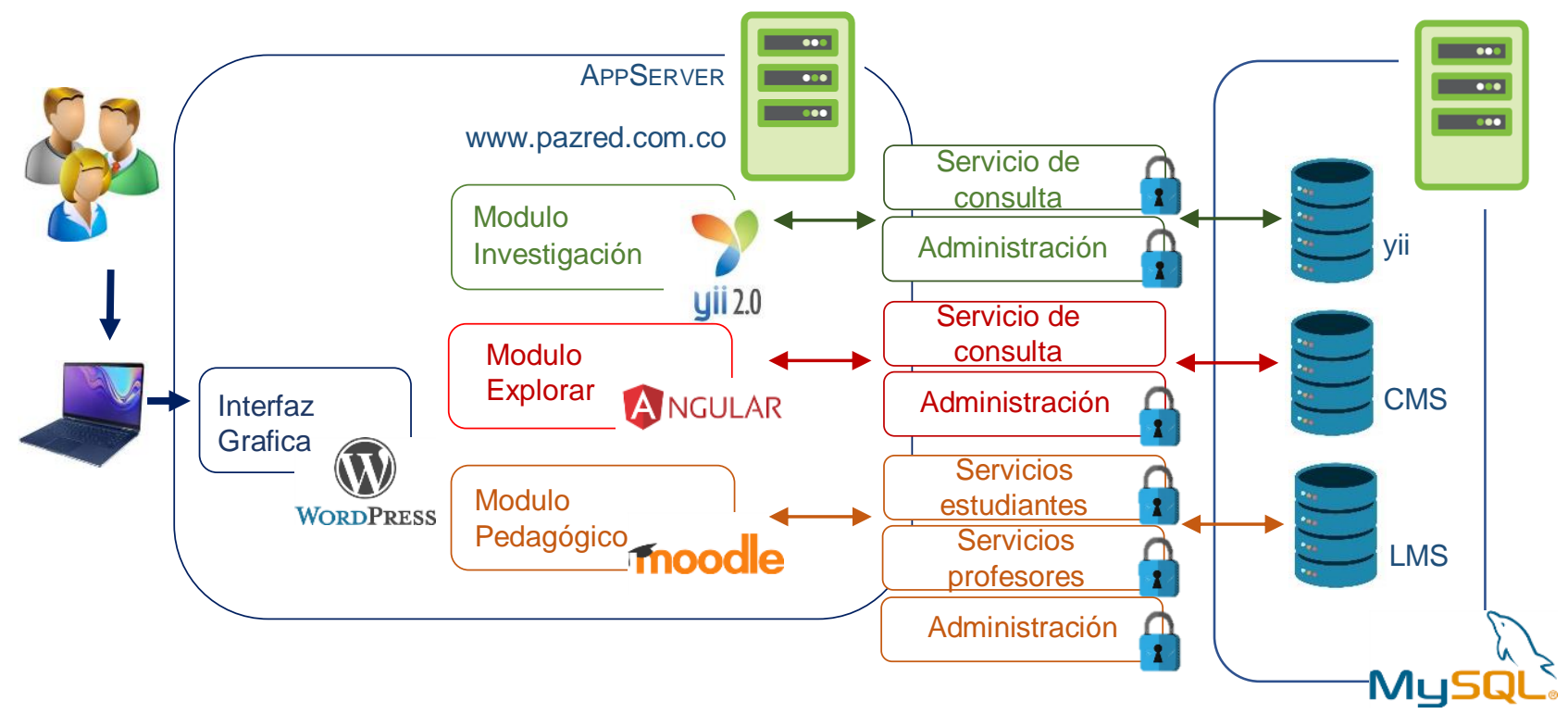

Fig. 2. Diagrama de componentes

Una vez el usuario ingresa al sitio web tiene acceso a todo el componente informativo. La plataforma cuenta con pestañas en el menú principal que permiten acceder al módulo de investigación y al aula virtual. Como se muestra en la Figura 2, cada componente tiene su propia base de datos, dado que los contenidos de cada componente son diferentes. Como se mencionó anteriormente, el componente investigativo almacena la información sin procesar recolectada en campo, el componente informativo cuenta con material seleccionado y editado, y el componente formativo cuenta con material editado con propósitos educativos.

\section{Interfaz Gráfica}

La Figura 3 y 4 presentan ejemplos de los elementos interactivos incluidos en el componente informativo de la plataforma PazRed. Todos los contenidos digitales se categorizaron de acuerdo con los elementos de la naturaleza, y se busca mantener esta metáfora a través de los elementos interactivos de la página. Por ejemplo, la página principal incluye un banner donde se despliegan fotografías con frases relacionas a la memoria histórica; en la zona izquierda del banner se despliega un menú con los elementos que permite navegar a través de sus significados y contenidos (ver Figura 3). Otro ejemplo de esta interactividad es un árbol incluido en la página principal, donde sus ramas se representan por cada elemento de la naturaleza; cuando el usuario esta sobre cada una de las ramas se despliegan diferentes álbumes de fotografías y textos cortos relacionado con el elemento seleccionado (ver Figura 4).

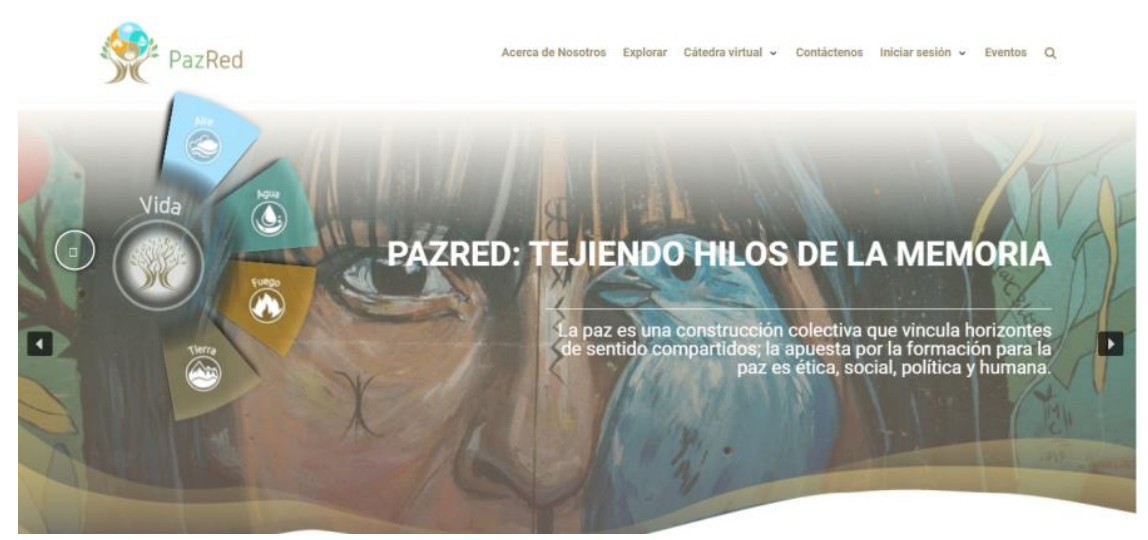

Fig. 3. Banner interactivo en página principal PazRed 


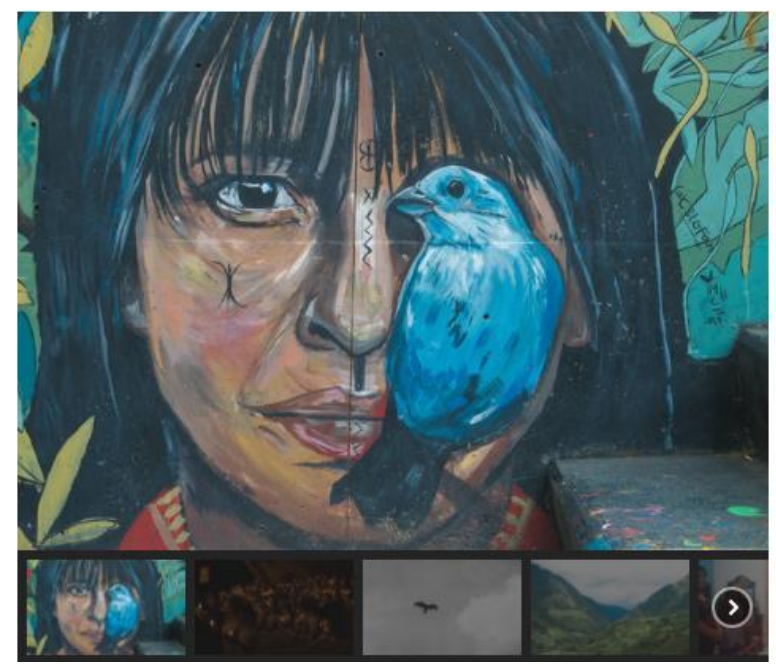

Fig. 4. Álbum de fotografías en página principal PazRed

\section{Percepción de los estudiantes}

Las Tablas 4 y 5 presentan los resultados de percepción de los estudiantes. Para analizar el grado de satisfacción o aprobación en cada una de las preguntas se presenta el porcentaje acumulado de las calificaciones 4 y 5 . En la Tabla 4 se resumen los resultados obtenidos en las dos encuestas: (I) la primera realizada una vez finalizado un módulo de la cátedra de PazRed, y (II) la segunda realizada al finalizar el curso. La primera encuesta fue respondida por 139 estudiantes y la segunda encuesta por 119.

En la Tabla 4 se puede observar la evaluación en cuanto a usabilidad de la plataforma. La mayoría de las respuestas tienen una valoración superior a 4, lo cual representa una alta aceptación de la plataforma. Adicionalmente, se nota una mejora significativa de la percepción de los estudiantes en los puntos relacionado con la presentación del sitio (pregunta 1), información encontrada en un clic (pregunta 4), claridad de los nombres de los enlaces (pregunta 5), y representatividad y claridad de los iconos (pregunta 7). La valoración de los elementos visuales como las imágenes, los textos y colores de la plataforma (preguntas 2 y 3) fuero muy bien calificados por más del $90 \%$ de los usuarios en ambas encuestas. Sólo en dos preguntas se obtuvo una calificación de 4 o 5 por menos del $80 \%$ de los usuarios en las dos encuestas. La primera de estas preguntas esta relaciona con la navegación de la página para volver atrás y avanzar sin usar los botones del navegador (pregunta 6). La segunda pregunta con una baja valoración fue la relacionado con la opción de buscar de la plataforma (pregunta 8). Estos dos aspectos están relacionados con la navegabilidad de la plataforma y, por tanto, requieren de una mejora como trabajo futuro. Referente a los contenidos digitales y el tema de paz, $100 \%$ de los estudiantes consideraron en la segunda encuesta que los contenidos desarrollan reflexibilidad y conocimiento en el tema (pregunta 9).

Tabla 4. Resultados de percepción de los estudiantes respecto a la usabilidad de la plataforma PazRed

\begin{tabular}{|c|c|c|c|c|c|c|c|}
\hline \multicolumn{2}{|l|}{ Pregunta } & \multicolumn{5}{|c|}{ \% de estudiantes por valoración } & \multirow{2}{*}{$\begin{array}{c}\% \geq \\
4\end{array}$} \\
\hline & & 1 & 2 & 3 & 4 & 5 & \\
\hline \multirow[t]{2}{*}{ 1. ¿Le parece adecuada la presentación y estructura del sitio? } & 1 & 2.2 & 2.9 & 7.2 & 33.8 & 54.0 & 87.8 \\
\hline & II & 0.0 & 0.0 & 5.0 & 27.7 & 67.2 & 95.0 \\
\hline \multirow{2}{*}{$\begin{array}{l}\text { 2. ¿Los colores de los textos en los menús son legibles y se } \\
\text { identifican claramente? }\end{array}$} & l & 2.2 & 2.2 & 3.6 & 23.7 & 68.3 & 92.1 \\
\hline & II & 0.0 & 0.0 & 1.7 & 19.3 & 79.0 & 98.3 \\
\hline \multirow{2}{*}{$\begin{array}{l}\text { 3. ¿Las imágenes que se presentan son adecuadas al mensaje que } \\
\text { se desea transmitir? }\end{array}$} & I & 0.7 & 0.7 & 2.9 & 20.9 & 74.8 & 95.7 \\
\hline & II & 0.0 & 0.0 & 2.5 & 17.6 & 79.8 & 97.5 \\
\hline \multirow{2}{*}{$\begin{array}{l}\text { 4. ¿Al hacer clic en algún contenido o enlace halló la información } \\
\text { que esperaba encontrar? }\end{array}$} & $I$ & 5.8 & 7.9 & 12.9 & 25.2 & 48.2 & 73.4 \\
\hline & II & 0.0 & 1.7 & 6.7 & 30.3 & 61.3 & 91.6 \\
\hline \multirow{2}{*}{$\begin{array}{l}\text { 5. ¿Los nombres de los enlaces son suficientemente descriptivos y } \\
\text { coherentes con el contenido en las páginas hacia las cuales llevan? }\end{array}$} & I & 2.2 & 7.2 & 7.2 & 27.3 & 56.1 & 83.5 \\
\hline & II & 0.0 & 0.0 & 4.2 & 23.5 & 72.3 & 95.8 \\
\hline \multirow{2}{*}{$\begin{array}{l}\text { 6. ¿Pudo encontrar la manera de volver atrás y avanzar sin usar los } \\
\text { botones del navegador? }\end{array}$} & I & 7.2 & 6.5 & 23.7 & 27.3 & 35.3 & 62.6 \\
\hline & II & 2.5 & 5.9 & 18.5 & 25.2 & 47.9 & 73.1 \\
\hline \multirow{2}{*}{$\begin{array}{l}\text { 7. ¿Los íconos presentes en el sitio, le parecen lo suficientemente } \\
\text { legibles, reconocibles, y explicativos? }\end{array}$} & I & 2.9 & 5.0 & 10.8 & 34.5 & 46.8 & 81.3 \\
\hline & II & 0.0 & 0.0 & 5.9 & 28.6 & 65.5 & 94.1 \\
\hline \multirow{2}{*}{$\begin{array}{l}\text { 8. ¿La opción de buscar le permitió encontrar la información que } \\
\text { quería encontrar? }\end{array}$} & $I$ & 5.0 & 7.2 & 18.7 & 29.5 & 39.6 & 69.1 \\
\hline & II & 3.4 & 3.4 & 15.1 & 30.3 & 47.9 & 78.2 \\
\hline \multirow{2}{*}{$\begin{array}{l}\text { 9. ¿Los contenidos que se desarrollan en la plataforma generan } \\
\text { reflexividad y conocimiento del tema central? }\end{array}$} & I & 1.4 & 0.7 & 3.6 & 29.3 & 65.0 & 92.6 \\
\hline & II & 0.0 & 0.0 & 0.0 & 21.0 & 78.9 & 100 \\
\hline
\end{tabular}


La Tabla 5 presenta los resultados de percepción final de la plataforma. Estas preguntas solo se realizaron a los estudiantes al finalizar la cátedra virtual de paz. Todos los aspectos evaluados fueron calificados con 30 más puntos como se puede ver en la Tabla 5. La experiencia en la cátedra, la pertinencia de las temáticas, los contenidos y en general la plataforma contaron con un alto grado de valoración por parte de los estudiantes. Finalmente, la Figura 5 muestra cual fue el contenido digital que más disfrutaron los estudiantes. Las historias de vida, las cuales corresponde a cortas biografías presentadas en formato de revista digital, fueron el contenido digital con mayor acogida. Para el $24 \%$ de los estudiantes, el contenido digital que más disfrutaron fue los podcast, y para el $13 \%$ los microrrelatos.

Tabla 5. Resultados evaluar la percepción final de los estudiantes sobre su experiencia en PazRed

\begin{tabular}{|c|c|c|c|c|c|c|}
\hline \multirow[t]{2}{*}{ Pregunta } & \multicolumn{5}{|c|}{$\begin{array}{l}\% \text { de estudiantes por } \\
\text { valoración }\end{array}$} & \multirow[t]{2}{*}{$\% \geq$} \\
\hline & 1 & 2 & 3 & 4 & 5 & \\
\hline 10. ¿Cómo califica su experiencia en la cátedra virtual PazRed? & 0.0 & 0.0 & 3.4 & 22.7 & 73.9 & 96.6 \\
\hline $\begin{array}{l}\text { 11. ¿Cómo califica la pertinencia de las temáticas abordadas respecto a la } \\
\text { educación para la paz? }\end{array}$ & 0.0 & 0.0 & 0.8 & 14.3 & 84.9 & 99.2 \\
\hline 12. ¿Cómo califica los contenidos digitales de la cátedra virtual de paz? & 0.0 & 0.0 & 2.5 & 20.2 & 77.3 & 97.5 \\
\hline 13. ¿Cómo califica la plataforma pazred.com.co? & 0.0 & 0.0 & 14.3 & 31.9 & 53.8 & 85.7 \\
\hline
\end{tabular}

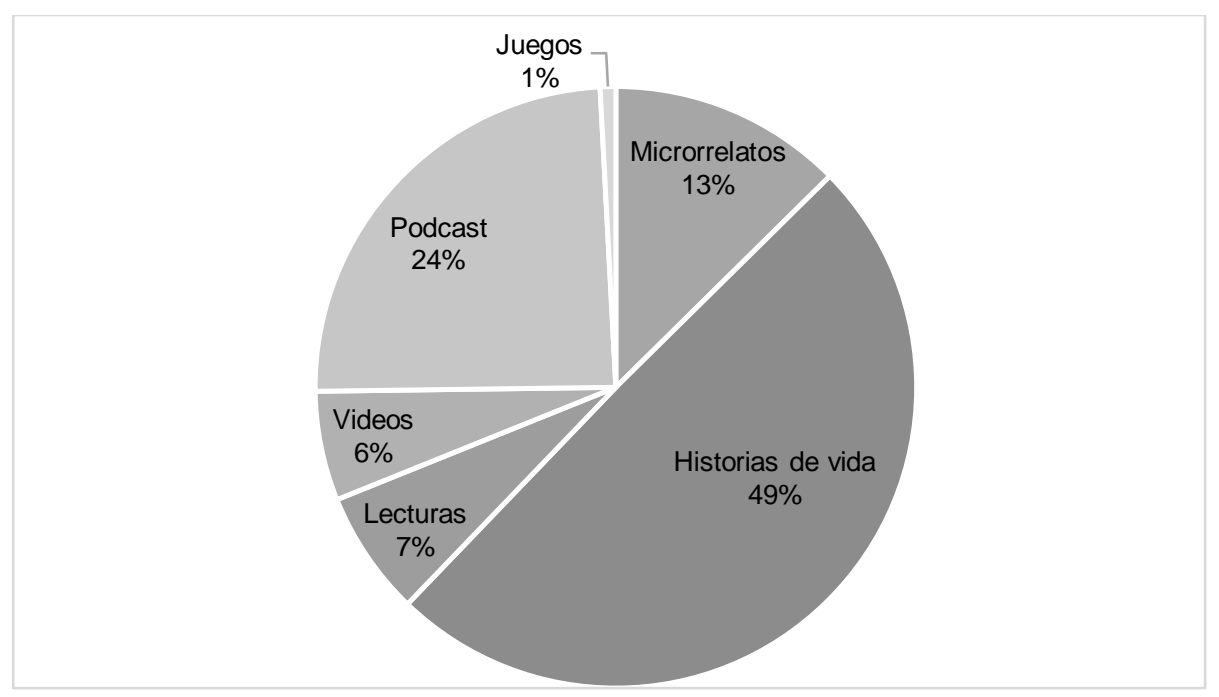

Fig. 5. Preferencia de los estudiantes sobre los contenidos digitales de la plataforma PazRed

\section{DISCUSIÓN FINAL}

Los requerimientos no funcionales de la plataforma virtual desempeñan un lugar central en el diseño de un escenario interactivo, reconocido como el espacio donde se lleva a cabo el diálogo de los usuarios con las tecnologías. Este espacio se compone de aspectos técnicos, sensoriales, comunicativos y emocionales que pueden aprovecharse para los procesos de enseñanza y aprendizaje. En este artículo se presentó una plataforma virtual que vincula los componentes interactivos con la educación para la paz que demanda un manejo de información sensible. La educación para la paz empleando TIC enfrenta diferentes retos, pero también ofrece la posibilidad de desarrollar contenidos digitales que faciliten el desarrollo de competencias ciudadanas. Estos espacios de formación no se limitan a ser repositorios, sino que se convierten en insumos para la sensibilización, la reflexión histórica y el desarrollo del pensamiento crítico, que va más allá de lo informativo.

Como se pudo dar cuenta en este estudio, las TIC en lo educativo posibilitan un nuevo paradigma, que requiere desarrollos y análisis. En primer lugar, el marco de interpretación donde se lleva a cabo el proceso formativo; la inmediatez, el acceso a la imagen como recurso pedagógico, los juegos, los podcasts, entre otros extienden el lenguaje de lo escrito a lo visual y sonoro, posibilitan registros que apelan al uso de otros sentidos. En segundo lugar, la relación entre los actores de los procesos formativos; la mediación de la pantalla invita a reconfigurar la forma como interactúan los estudiantes entre sí y con el docente. Y, en tercer lugar, el alcance de los contenidos que van más del escenario del aula, donde dejan de ser limitantes el espacio y el tiempo posibilitando diálogos que van lo local a lo global. 
La plataforma PazRed es una primera aproximación de generar otros modelos pedagógicos y de enseñanza para las ciencias sociales, especialmente para las cátedras de paz y el aprovechamiento de desarrollos tecnológicos. La plataforma propuesta obtuvo una excelente acogida por parte de los estudiantes, en los aspectos relacionados con el uso de las metáforas, los contenidos digitales como los podcast, microrrelatos e historias de vida. A pesar de ello, continúa siendo un desafío el rol del docente y el acompañamiento que se espera al proceso de formación. De manera adicional, la evaluación se presenta como un reto que demanda ampliar el alcance de las TIC.

\section{CONCLUSIONES}

Este articulo estudia las potencialidades de las TIC y la interactividad para el desarrollo de procesos educativos en temas de paz. De acuerdo con el trabajo presentado y a los resultados obtenidos, se pueden plantear las siguientes conclusiones principales:

La interactividad juega un papel fundamental como componente pedagógico en procesos de educación virtual. La interactividad permite la incorporación de diversos lenguajes en los ambientes virtuales: textos, fotografías, audios, videos, gráficos, y esa diversidad de lenguajes permite abordar con mayor sensibilidad y reflexividad temáticas relacionadas a memoria histórica reconstruida a partir de las narrativas de los actores de conflictos armados.

La plataforma virtual propuesta PazRed soporta la educación para la paz en el país, a partir de espacio interactivos digitales, que buscan dar a conocer la reconstrucción de la memoria histórica desde actores del conflicto armado. Esta plataforma, diseñada inicialmente desde las narrativas de una región de occidente de Antioquia, es escalable a otras regiones del país, y por tanto es un insumo inicial para apoyar los esfuerzos por el desarrollo de competencias ciudadanas.

Sin embargo, al ser la educación para la paz un tema de alta complejidad y sensibilidad, se evidencia una necesidad por otros desarrollos tecnológicos (plataformas web, móviles, contenidos digitales, entre otros) que soporte estos procesos pedagógicos. En la educación para la paz no se busca la apropiación de conocimientos, sino el desarrollo efectivo de competencias ciudadanas y de habilidades para afrontar conflictos. Por esta razón, los desarrollos tecnológicos deben aprovechar las potencialidades de las TIC para desarrollar espacios perceptivos y emocionales.

\section{AGRADECIMIENTOS}

Esta investigación fue financiada por Minciencias, proyecto "Cátedra virtual de paz PAZRED: Tejidos de la memoria en el Occidente de Antioquia", código FP44842-459-2018.

\section{REFERENCIAS}

Area, M., y Pessoa, T., De lo sólido a lo líquido: las nuevas alfabetizaciones ante los cambios culturales de la Web 2.0, https://doi.org/10.3916/C38-2012-02-01, Comunicar: Revista Científica Iberoamericana de Comunicación y Educación, XIX(38), 13-20 (2012)

Barash, J., Collective memory and the historical past, University of Chicago Press, Chicago, Estados Unidos (2016)

Bahreini, K., Nadolski, R., y Westera, W., Towards real-time speech emotion recognition for affective e-learning, https://doi.org/10.1007/s10639-015-9388-2, Education and Information Technologies, 21(5), 1367-1386 (2016)

Cabero, J., y Llorente, M., La interacción en el aprendizaje en red: uso de herramientas, elementos de análisis y posibilidades educativas, https://doi.org/10.5944/ried.2.10.995, RIED Revista Iberoamericana de Educación a Distancia, 10(2), 97-123 (2007)

Castells, M., Networks of outrage and hope: social movements in the internet age, John Wiley \& Sons, Cambridge, Inglaterra (2015)

Cenacchi, M., La accesibilidad web en el marco teórico y metodológico del dispositivo hipermedial dinámico: acerca del caso memoria y experiencia Cossettini, Revista IRICE, 28(28), 37-61 (2015)

Çikrıkci, Ö., The effect of internet use on well-being: meta-analysis, https://doi.org/10.1016/j.chb.2016.09.021, Computers in Human Behavior, 65, 560-566 (2016)

De-la-Hoz-Franco, E., Martínez-Palmera, O., Combita-Niño, H., y Hernández-Palma, H., Las tecnologías de la información y la comunicación y su influencia en la transformación de la educación superior en Colombia para impulso de la economía global, http://dx.doi.org/10.4067/S0718-07642019000100255, Información Tecnológica, 30(1), 255-262 (2019)

Fainholc, B., The interactivity in distance education, Tweeted, Buenos Aires, Argentina (1999)

Fernández-Rodríguez, J., ODS 16: paz, justicia e instituciones fuertes, bie3: Boletín IEEE, (11), 970-1001 (2018)

Freire, P. Pedagogía de la esperanza: un reencuentro con la pedagogía del oprimido, Siglo XXI Editores, México D.C, México (2014) 
García, N., Disposal and reinvention: citizenship in an era of electronic capitalism, https://doi.org/10.1515/culture-20180025, Open Cultural Studies, 2, 273-284 (2018)

Garzon, J., y Acevedo, J., Meta-analysis of the impact of augmented reality on students' learning gains, https://doi.org/10.1016/j.edurev.2019.04.001, Educational Research Review, 27, 244-260 (2019)

Gil, A., Acción colectiva en contextos de conflictividad, Circunstancia, 10, 3-55 (2006)

Gómez, A., Una apuesta educativa para América Latina: educación para la paz, Revista Latinoamericana de Estudios Educativos, 45(1), 17-62 (2015)

Gómez, A. y Hernán, D., Nuevas generaciones y viejos problemas: tensiones escolares y cambios culturales, https://doi.org/10.19052/ap.2959, Actualidades Pedagógicas, 1(67), 55-71 (2016)

Gravante, T. y Sierra, F., Ciudadanía digital y acción colectiva en América Latina: una crítica de la mediación y apropiación social, Revista nuestrAmérica, 6(12), 79-100 (2018)

Guney, Z., Considerations for human-computer interaction: user interface design variables and visual learning in IDT, https://doi.org/10.18844/cjes.v11i4.4481, Cypriot Journal of Educational Science, 14(4), 731-741 (2019)

Hymel, S. y Darwich. L., Building peace through education, https://doi.org/10.1080/17400201.2018.1535475, Journal of Peace Education, 15(3), 345-357 (2018)

Iqbal, M., Saleem, Y., Naseer, K., y Kim, M., Multimedia based student-teacher smart interaction framework using multiagents in elearning, https://doi.org/10.1007/s11042-017-4615-z, Multimedia Tools and Applications, 77(4), 5003-5026 (2018)

Lévy, P., Collective intelligence: for an anthropology of the cyberspace, Basic Books, New York, Estados Unidos (1997)

Le, H., The reproduction of "best practice": following escuela nueva to the Philippines and Vietnam, https://doi.org/10.1016/j.ijedudev.2018.02.005, International Journal of Educational Development, 62, 9-16 (2018)

Lorenzo, F. y Martínez, F., Interactividad: revisión conceptual y contextual, https://doi.org/10.7195/ri14.v8i1.277, Revista ICONO14 Revista científica de Comunicación y Tecnologías Emergentes, 8(1), 9-21 (2010)

Mannay, D, Métodos visuales, narrativos y creativos en investigación cualitativa, Educatio Siglo XXI, 35(2), 403-406 (2017)

Marschall, S., The virtual memory landscape: the impact of information technology on collective memory and commemoration in Southern Africa, https://doi.org/10.1080/03057070.2013.763325, Journal of Southern African Studies, 39(1), 193-205 (2013)

McEwan, P., y Benveniste, L., The politics of rural school reform: escuela nueva in Colombia, https://doi.org/10.1080/02680930110087816, Journal of Education Policy, 16(6), 547-559 (2001)

Okolo, C., Englert, C., Bouck, E., y Heutsche, A., Web-based history learning environments: helping all students learn and like history, https://doi.org/10.1177/10534512070430010101, Intervention in School and Clinic, 43(1), 3-11 (2007)

Paredes, H., Segura, M., Orozco, M., y Caicedo, H., The history of the subject of peace in the department of Cauca from 1962 to 2017, a proposal for its reinforcement and effective implementation, https://doi.org/10.18041/23823240/saber.2018v13n2.4598, Saber, Ciencia y Libertad, 13(2), 21-35 (2018)

Petras, V., Hill, T., Stiller, J., y Gäde, M., Europeana - a search engine for digitized cultural heritage material, https://doi.org/10.1007/s13222-016-0238-1, Datenbank-Spektrum, 17 (1), 41-46 (2017)

Raja, R., y Nagasubramani, P., Impact of modern technology in education, https://dx.doi.org/10.21839/jaar.2018.v3S1.165, Journal of Applied and Advanced Research, 3(1), 33-35 (2018)

Scolari, C., From (new) media to (hyper) mediations: Recovering Jesús Martín-Barbero's mediation theory in the age of digital communication and cultural convergence, https://doi.org/10.1080/1369118X.2015.1018299, Information, Communication \& Society, 18(9), 1092-1107 (2015)

Torres-Madroñero, M. y Torres-Madroñero, E., PazRed: una propuesta de educación virtual para la formación de estudiantes universitarios en competencias para las ciencias sociales, https://doi.org/10.22430/21457778.1715, Trilogía Ciencia, Tecnología y Sociedad, 12(24), (2020)

Thakur, R., y Pandey, U., The role of model-view controller in object oriented software development, https://doi.org/10.3126/njmr.v2i2.26279, Nepal Journal of Multidisciplinary Research, 2(2), 1-6 (2019)

Vicentini, M., y Kahn, K., Life stories as a museal fact treated by information design in digital curation at museu da Pessoa, Biblios, (75), 16-27 (2019) 